\title{
DETERMINING FACTOR OF E-MARKETING IN HUNGARY
}

\author{
Katalin Tari
}

\begin{abstract}
In the world of marketing, innovative solutions and new development opportunities will always come into play. They are major factors in improving the competitiveness and for consumers needs as well. The aim of the study is to examine and compare the efficiency and effectiveness measurement of the online campaigns. This study demonstrates theoretical approaches. Moreover, it points to the practical application differences. The paper wants to rank the effectiveness of online advertisement with the currently used Hungarian online measures (index). This index is explained in this study by using the available practical literature. Procession of the practical literature will include the online advertising methods ranked by the CPM (Cost per 1000 Impression) which will imply the effectiveness of ads. My research methodology followed qualitative strategy, on the base of content analyses of in-depth interviews of online experts $(N=7)$. I recorded the conversation and then I transcribed the data. My questions were structured. The questioning went between 10 March and 18 May 2016. Seven persons have taken part in the research. The in-depth interviews will be conducted with the consent of online shop managers and leaders of creative and advertisement agencies. Each interviewee serves the business-to-business trade. My aim is to present same of the Hungarian online advertising trends from 2016. This indication will show the effectiveness of different marketing tools and the reach of online experts. This research point out the possible measuring methods and indications.
\end{abstract}

Keywords: e-marketing, online marketing, Hungarian trends

\section{Introduction}

Development of innovative solutions and efficacy and developmental opportunities of marketing and its tool-system have an important role in marketing - in my case the online marketing - from the point of view of all sectors of economics. The appropriate positioning and segmenting of the target market, the usage of the properly structured sales promotion, as well as differentiated price and product policy are well known tools of increment of efficiency. These play an important role in improving competitiveness as well as satisfaction of customers' demands. What kind of transition are I witnessing? This topic has higher priority while the most developing industrial branch today is the emerchandizing. Reviewing the events of the last decades, right after the radical changes affecting the economy and with it the sector of marketing, now I live in an essentially new boom of digital age which is also called the 'golden era of e-trade' (Virányi, 2014).

This intensive increment - on the base of estimations - will entirely define the formation of the economy until 2018. On the base of the research of 'emarketer.com', the number of regular internet-users is going to reach the half of the population of Earth in two years. Therefore, the number of the internet-users will slow down in the future (eMarketer, 2015). The other reason for decline is the fact of the finite element number, which is the population of Earth. Related to Hungary, this slowing effect could already 
be experienced last year (Majláth and Kelemen-Erdős, 2015). In 2010, 55\% of population of the country was regular internet-users, while $72 \%$ of them have been using the internet regularly since 2014 and $74 \%$ of them were in 2015 (KSH, 2016). I am going to write more about the slowing increment in section 'Introduction' in more detail, later. The firms build an increasing confidence in internet-users with proper utilization of online communication tools (Feather, 2013). The number of interactions is growing between the participants which may support reports of experience gained by word of mouth. The online firms appearing on the online market can target a growing online customer layer with flexible opening hours and comparable prices; with various product range; by easy operation as well as everyday usage of smart phones (Kaushik, 2010).

\section{How to work on the online market more effectively?}

The first step is to make the company's aims clear. The revenue growth and reputation, as well as popularizing, are the focus of marketing campaigns. The support of these aims enhances a more effective planning and targeting of campaigns by the most determining elements of the recent online age. In addition, the selection of the marketing channel is an essential factor. These aims are impacted by the target group, characteristics of the product and/or service, the competitors, the budget, the features and measurement of online media as well as other unique factors such as time, urgency, the synergy-effects or the creative ideas.

The effectiveness of the campaign, which means the number of realized purchases, can be measured by tools that have been used for many years among marketing agencies. This means there are several possibilities of the personalized optimizing tools. For example, SEO, PPC also known as CPC, the follow-up of bounce index, conversion optimization, click through rate, call to action (CTA) and then the analyses and interpretation of incoming data as well as conclusions (Kaushik, 2007). These last three factors will be discussed later in my study. Search engine optimization (SEO) has basically two main work phases. One is the optimum content and structure of the website. Furthermore, the other is the link promotion. The meaning of Cost Per Thousand Impressions (CPM) is the cost per 1000 impressions. Cost Per Click (CPC) allows the maximum amount of clicks what the company need to pay (Fehér and Gombos, 2016). Call to action (CTA) button is if it encourages a visitor to leave the website. For example: click for registration, download or more information (Fehér and Gombos, 2016).

Everyone can launch the idea of running an online shop along with the broad proliferation of online trends in Hungary. Today, it is much easier to prepare and support the company's decisions, which can reduce risks or open up towards unprecedented cross-border markets. The presenting companies could follow-up with the customer, analysing antecedents and actions so they can have a highest offer with their personalized products and/or services. Then these firms can achieve $100 \%$ conversion index - which is actually still inaccessible (Fehér, 2013).

My research goal is to demonstrate the most frequently used tools at the online market as well as the differences in practice between online and offline marketing campaigns on business-to-business market in Hungary. Further aims are to evaluate the effectiveness and influence of them. My results are based on content analyses of structured in-depth interviews, recorded in professional context (Ghauri and Gronhaug, 2010). 


\section{Short review on the Hungarian e-trends}

As mentioned in the introduction, I wish to present the reasons for the slowing growth of Internet users, during the presentation topic. The migration and poverty there could stand in the background of the slowing pace of growth. In addition, the two groups of Internet surfers should be separated, in the beginning. Namely, those who do not buy, and those who buy online, since they are direct participants in the economy. While the figures show slowing growth of number of users, then the number of online shoppers will gradually grow. The intensive growth rate here has lagged in my country, so it is now gradually distributed throughout a prolonged period. The companies using online communication tools correctly are building an increasing confidence among users, the number of interactions that supports experiential reports obtained by the oral tradition in a family/friend expression is increasing between the participants. It means that the customers are sharing their preferences to each other (Malik and Sachdeva, 2015). By flexible opening hours and comparable prices; with a diverse range of products and easy operation and by extensive display support or by everyday use of smart phones the company is more widely and more efficiently able to target the customer base, if it advertises on online market. This growth is associated with the relatively positive evolution of the total costs and revenue (Kotler and Keller, 2006). Conversion index shows the fixed cost recovery. Therefore, it is important to clarify the concept for this reason, and also because of correct interpretation of my questions. The conversion index is not meaningful as itself, because it is necessary to define a conversion goals and research question or questions, first (Fehér, 2013). I use the conversion index most commonly, in general form in case it shows the number of realized purchases, usually examining the online market aspects. The $3-5 \%$ of access can be stated as a good achievement on the Hungarian online market, which means 4-5 purchases from 100 accesses, e.g. clicks (Miller - Washington, 2009). In addition, I calculated the access (clicking) conversion on the base of private experiences - gained as a media designer 1 year long - of the ad (banner / image), DM, search engine optimization (keyword) or sub-page of the website (landing page) accesses. The performance and optimizing of marketing campaign can be analysed at any time even including free programs, as Google Analytics, Google Adwords (Miller and Washington, 2009). These free or paid analytical evaluations summarize the company's statistics for that given period and point out the results of the breeding rate of return (Szabó, 2008). After analysing the statistics, the business decisions can be facilitated, the process becomes more predictable, and the key is that individual attitudes and habits and range of features of target group of the product and / or service can be formed which largely supports the company's competitive and efficient operation. Thus, this indicator as a separate segment shows the efficiency or effectiveness of used online marketing tools. To choose the right one, I need to clarify the conversion goals (Saleh and Shukairy, 2010). One of the most popular targets is to reach - really - online customers had to purchase, acquire subscribers, with participation in the sweepstakes, as well as market research and survey questionnaire is included (Bíró, 2009).

\section{Research method}

My research methodology followed a qualitative strategy, on the base of content analyses of in-depth interviews of online experts $(\mathrm{N}=7)$. The first author recorded the conversation and then I transcribed the data. My questions were structured. The questioning went between 10 March and 18 May 2016. Seven persons have taken part in 
the research who were middle and/or top managers and had at least four years of experience and maximum fifteen. Their job activities included planning, leading and following-up marketing and/or creative campaigns, together with analyses, online legal advising, retargeting, optimization services and running an online shop. Each interviewee serves the business-to-business trade. Their average age is 31 years. The oldest interviewee was 38, the youngest one was 25 years of age. All interviewees graduated from higher vocational education in economics, three persons received Master degree and four persons received a Bachelor degree. All were residents in the capital city, Budapest, except two persons, who also live in the state "Pest". Two female and five male persons responded during the in-depth interviews. Two respondents asked for anonymity, but I explain further content in the following (position, work experience, scope of activity).

\section{Analyses of experts background of interviewees}

(1) My first interviewee: he is a social media expert. Previously, he has worked for Kirowski Iso Bar Ltd., one of the biggest media agencies, as a marketing advisor on email, online and social platforms. Recently, he is dealing with online marketing and creative campaigns with a team covering seven countries, as a Head of Social Media. He intends to be an effective intermediary between companies' ordering campaign and among consumer purchases - which has been precisely positioned by him - gained along with the joint work.

(2) My second interviewee: he manages the one of the widest Internet advertising networks of South-East Europe as an ad-serving leader. Since the founding of the company in 2006, it has become an exclusive partner of international and regional actors; they cover eight countries. Today the company is a quality partner of such publishers as MSN Messenger, Windows Live, Facebook and Miniclip, as well as leading local publishers. They treat the marketing campaigns uniformly to ensure the highest level of service at various surfaces, such as display banners, rich media, search and video.

(3) My third interviewee: he is a recognized Managing Director and an Internet and online legal expert. He founded the business with another person by having decadeslong legal experience. The company published quality certificates, as well as a book on the subject, besides online legal advisory.

(4) My fourth interviewee: considering his current position, he is responsible for the new markets (CEE Head of New Business). He started his unbroken career in 1999. Initially, he worked as an independent financial expert. Then, he has been working for companies providing online payments, mainly, as well as banking services; and secondly for a company, bringing together the global technology services, concerning the online sphere. The company is resident in Austria from 2016 but can be found on the Hungarian market also, with diverse range of activities.

(5) My fifth interviewee: his current position is leader of a marketing department at a Conversion Optimizer tool/software provider company. The company's services are like popup, Call to Action, which means calling to action trying to save the departing visitors, by a CTA window, thus increasing the access rate of conversion index. The promised conversion by them is 3-4\%, which is 3-4 purchases from 100 visitors. The company is developing a growing pace, as it is marketing services not only individually, but as a package; their services are also available bringing together, for example, companies operating web shop or server. 
(6) My sixth interviewee: he is the Head of PPC, i.e. Pay per Click team leader, so he knows a lot about advertising and statistical analysis side of Etarget, Google. In addition, web pages and web operations, SEO optimization is also addressed. Besides the company's online campaigns - it is also available as a special package offer - it sells Yellow Pages phone books' print advertising surfaces as well.

(7) My seventh interviewee: he has been working as a media supervisor for a classical media agency for years, where they manage both offline and online ads, however they do not deal with creative tasks. The online activity of them is fully extended; they offer AdWords, banner display, EDM, Facebook, mobile applications, online video, YouTube and search engine optimization inclusions.

\section{Questions to be answered}

(Q1) Question one: can the professional web experts provide a targeted, personalized offer for companies in any sectors of industry at any time, in order to reach the proper target group?

(Q2) Question two: do starting a new web shop promises a proof of income in 2017, as it is an easy way to produce firm revenue for a business, nowadays?

(Q3) Question three: is the conversion index a reliable measure?

(Q4) Question four: which are those measurable online marketing campaigns that determine the Hungarian online market? Is a sole online presence sufficient in order to achieve a secure corporate success?

(Q5) Question five: by various assurance certifications - quality product, data protection, legal compliance, ensuring low price, etc. - stated on the web site the buying propensity can be increased - and thus also the extent of the conversion index - in addition, arising mistrust can be reduced, as well.

All of the respondents said that whether I serve the business or customer sector, besides the online advertising and optimizing methods the campaign should be supported by offline activities. These can be divided into two groups on the base of answers given by each respondent. The first is the replacement of the personal contact which can be experienced during the online activity. One of the means of supporting the online activity is related to this is the thorough and precise work of customer service or the active participation in professional conferences. Each of the respondents consider important to disclose the firm's activities and opportunities, even as a presenter. Including this, a typical way of gaining customers is tendering which is also based on personal relations. The other group - examined by me - extends mainly to the B2B business trade. Here, the offline scopes of activity are grouping around the topic of education: trainings, newspaper appearances - like professional articles, interviews, case studies, etc. - or the opportunity of personal advisory. The conference participation also belongs to is, partially, in case it demonstrates the analyses of their activities with educational aims. The result of the survey - because the low number of items and its composition - is non-representative.

The interviewees were talking about the most important elements of the optimal and effective online marketing campaign, including the conversation index and involuntary published data of web shop visitor, like Google or Gmail account, the logged profile on social media sites, etc. and statistical analyses of my browser - which activities strengthen each other, closely. In case I analyse the reachable statistics of a 
potential customer properly, the conversation index of us will increase quickly supporting the strengthening competitiveness.

\section{Results}

In this chapter I briefly summarized the previously introduced questions.

(Q1) Question one: can the professional web experts provide a targeted, personalized offer for companies in any sectors of industry at any time, in order to reach the proper target group?

The campaign implemented 'at any time' is neither expedient not profitable because it is important to consider the external and internal conversions as to reach the aims in a simple and effective way. Despite of this - as an example - I can meet a customer who wants to run his or her banner tomorrow already which can be realized with the staff available, however, but the optimal level of effectiveness cannot be reached this way, because the majority of its target group is on summer holidays, nationwide, and that's why they use the Internet less often. I should consider such nonfactors like the time available or timing. Differentiating is needed, because the timing of the campaign depends on cost frame available in a great extent. Each interviewee, except one, told me that he cooperates with other companies if not directly but indirectly as a so called intermediary, convening the proper partners as to reach a successful campaign. The only exception is a group leader who manages the Facebook advertising platforms in 8 countries. He never meets this problem, because as a marketing agency, they are mandated all the time. They employ ready materials during their work and they do not offer out because they are overloaded, usually. Studying the questions further, the reaching of 'any industrial sector' occurred to me as a questionable one, but during the in-depth interviews conducted with colleagues of the agencies it has been revealed that they are able to serve 'any industrial sectors', indeed, recently. If not, then they can solve the problematic situations along with their social capital, as well. Obviously, a newly competing minor creative marketing agency (8-10 persons) would not do it well. My last interviewee works with 12 fellows at a company which has been existing for 15 years, already. He also suggests the further recommendation and supports the cooperation with other companies in order to reach the common marketing aims, customized to the orderers' wishes. Thus, the trustworthiness, which is being built during the years and projects is an important factor between the experts. In case of the online marketing campaigns the investments on the best opportunities can be lost if they are not timed, positioned or segmented properly. I extend my research on visiting minor agencies with maximum 8-10 persons, in the future. It is necessary for improvement of efficiency the before mentioned - proper positioning and segmenting to which the adequate professional knowledge is provided for business-to-business members. In case I intend to reach the customers directly as web shop operators, worth to ask for advice or control of a professional online marketing expert even then, in order to reach an infallible success. It is also important to pay attention to the product policy, the competitors, the new trends and customized sales promoting, besides the optimal timing. The majority of the interviewees (5 persons, respondents 1,2, 5, 6 and 7) stated, that in order to such an excellent operation, the agencies utilize analytical tools which not only monitor and analyze during surfing but conclude to possible outputs, e.g. the future purchase decisions. The program is based on sophisticated system theory which is continuously developing. The aim of the analytical programs is the optimizing and increment of effectiveness, thus the enhancement of competitiveness, as well. My seventh interviewee 
said that there are threats, the so called 'ghost-accesses' against of which the firm has been succeeded so far. This means that they apply a permanent monitoring to filter the click-generating programs. All of this is carried out by a computer alarm program which should be upgraded continuously.

(Q2) Question two: do starting a new web shop promises a proof of income in 2017 , as it is an easy way to produce firm revenue for a business, nowadays?

My second question has not been accepted because although it is a possible 'easy' way to gain, however, I can be mistaken in many aspects without taking into account the before mentioned external and internal conversion factors. On the base of analyses of experts' interviews, the interviewees - except 2 of them - named the income realization and the long term operation as 'easy' if the adequate social capital and financial resources are available. So if the company can afford money for marketing and it knows which media agency to turn to, then the 'easy going' is guaranteed. In case they do not avail the services provided by agencies, then a necessary condition is the targeted professional knowledge, such as online marketing, IT, marketing, logistics, bank sector and continuous mapping, analyses and development of them in order to appear and retain on the online market meeting the permanent innovation.

(Q3) Question three: is the conversion index a reliable measure?

My third question proved to be true after the answers. The $100 \%$ of online experts I interviewed agreed with my statement. In my view, however, beyond the 'spirit-access sites' - which is filtered by agencies by an alarm program based on the IP address further problems could arise with respect to the recontrol. There is a risk of the sole use of a single conversion value, as it distorts the results-for example, if an ad is clicked just by chance, or the cursor automatically adjusts and starts. They reach a separate count for the program, but in reality they are random events, of which you will never buy. When I asked it right after their response, all of them said that this failover occurs, indeed, but it is not common, and the optimization software can be set so sophisticatedly that access of actually not relevant consumers is almost completely excluded.

(Q4) Question four: which are those measurable online marketing campaigns that determine the Hungarian online market? Is a sole online presence sufficient in order to achieve a secure corporate success?

Nowadays, the three most popular trends of Hungarian online market-offers in 2016 are the thematic, personalized online materials - such as courses, downloadable training materials and e-mail, or the web personalization. In addition, it has been said that the proper use of content marketing can increase my accesses, and my search engine optimization - such as application of a blog, a blog post promotion, the guest blogging, etc. In addition, I got homogeneous results related to the business-to-business exchanges, in the selection of channels used in practice in the offline area, typically. Access to online conferences and professional presentations - for example: Conversion World have become instruments of development of productivity, as usual. In association with it, the surveyed companies place a great emphasis on article publishing and advertising opportunities of trade journals. The use of these two offline channels are defining scopes of activities in corporate reputation as well as in widening the clientele.

(Q5) Question five: 'By various assurance certifications - quality product, data protection, legal compliance, ensuring low price, etc. - stated on the website the buying propensity can be increased - and thus also the extent of the conversion index - in addition, arising mistrust can be reduced, as well.' 
I got homogeneous result regarding the topic, again, after analysing 4-1 in-depth interviews of online experts. All respondents used the answer-combinations 'yes' or 'yes, of course' - without hesitation. Although this result is reliable, as they are experienced professionals, it is not a representative one. I spread the number of interviewees, and as well as I intend to ask also consumers within the framework of a standardized questionnaire.
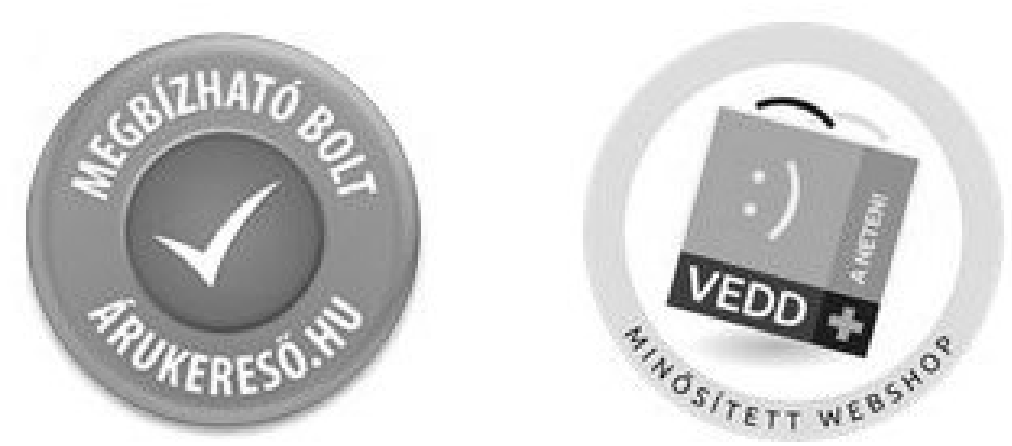

Figure 1 Logos of the "reliable shops" in Hungary

Source: https://www.primanet.hu/images/upload/image/megbizhato-bolt-minositettwebshop-630px.jpg, downloaded: 31.03.2017

\section{Discussion}

There are so many e-trends all over the world but we have to take care about the most important one. What is comfortable to the consumer that will be for sure a good strategy to the firms too? For example the certifications are important. Moreover, there are many blogs too. Blogs and Facebook Fanpages are platforms to help the communications between consumers and customers but between people and companies too. They are 'multidirectional communication' platforms. These mean that these platforms can help to orientate to the customers very easy and fast about what kind of product and/or services liked another customers or which are the cheapest. Therefore, the companies have to use online complaint management because they have to solve the problems if the customers have problems with the product and/or service. There are many effective strategies to save these kind of situations too. For example, firms are giving written feedbacks to say 'excuse us, we would like to help you solve your problem what you have after that you have got the product and/or service' on their blogs or Facebook sites too. Moreover, they give discounts, gift cards or any another compromises to their 'injured' customers. If somebody would like to work online than have to

- be fast: respond to competitors and give feedbacks to customers in 24 hours,

- be claim and patience: because customer has always right,

- be clear and give personalized product and/or service and use web personalization: give everyone what they need and communicate how they want,

- use downloadable training materials and e-mails (learn, learn, learn),

- use content marketing and certifications,

- analyse your web site and your customers: because online marketing campaign are measurable. You can use the analyses during your promotions and discount campaign. 


\section{Conclusion}

The most important aims of this paper were to research new, innovative, productivity-enhancing options and their tools, to estimate the volume of their efficiency and reliability, as well as introduce the Hungarian market index measurement used in practice. I found the current conversion rates correct based on my research, but nevertheless I rejected the questions of bias 'ghost' on purpose. From the point of view of my investigation of the effectiveness of online marketing, the first step of a start-up web shop is to fix the web site content and formal requirements. The next step is to develop it before advertising the start of the distribution. Then, following-up and comparing the continuous statistics, the individual consumer habits, attitudes and characteristics that are relevant to the company's product and/or service terms can be emphasized. Therefore, despite my results and optimization programs, I have to continue testing the target groups, permanently, by changing several promoting tools as well as some design components like varying the layout or colors. The consumer behaviour groups established this way follow a relatively similar behaviour pattern. Based on the adequate number of access statistics, a more targeted and effective marketing message can be fed to the visitors, by which the purpose of the message can have a greater chance of success, and the shopping phase continuing testing can be reached more rapidly.

Another aim of this study was to introduce the most frequently used tools and measurement capabilities of Hungarian online and offline marketing campaigns, relevant in practice, in business-to-business market. Among my respondents, there were the participants of $\mathrm{B} 2 \mathrm{~B}$, and members of the two-player supply-chain, where the trader, the retailer and the consumer are also located among partners. My further goal was to emphasize their influence and effectiveness, as well as potential dangers. The web shop operators take a great care to show the full online extensions, paying particular attention to mobile to ensure adequate competitiveness. In addition, the sleek design, user friendly, concise, yet informative content marketing is essential to support both business and consumer (B2C) sectors (Loveday and Sandra Niehaus, 2007). My conclusions have resulted in online experts' circles, based on analysis of the content of structured in-depth interviews. The limitation of my study was the low number of the elements that I would like to expand in my next research. After completing the recent phase of the study, I believe that the online market research topic still contains a lot of alternatives and research potential. The picked up online shopping is to peak until 2018-2020 (eMarketer, 2015), which is why I will research the topic further. In the future, I plan to observe, analyse and compare the changes in the direction of the development of the two nationalities involved.

\section{References}

Bíró P., 2009. Marketing nélkül nem megy, Budapest

eMarketer, 2015. Internet to hit 3 billion users in 2015. Downloaded: $19^{\text {th }}$ of April, 2016. from the page of http://www.emarketer.com/Article/Internet-Hit-3-Billion-Users$\underline{2015 / 1011602}$

Feather J. P., 2013. The Information Society. A study of continuity and change, Sixth edition, London, pp. 23-38.

Fehér M., Gombos Zs., 2016. Facebook hirdetés lépésről lépésre, Online Marketing Akadémia, pp. 6-67. 
Fehér M., Gombos Zs., 2016. Verhetetlen remarketing technikák, Online Marketing Akadémia, pp. 5-68.

Fehér, M., 2013. Mi fán terem a konverzió? downloaded: $5^{\text {th }}$ of May, 2016. from the page of: http://www.online-marketing-akademia.hu/blog/2013/02/mi-fan-terem-akonverzio-1/

Ghauri, P., Gronhaug, K., 2010. Research Methods in Business Studies: A Practical Guide. Fourth Edition, FT-Pearson

Hungarian Central Statistical Office (KSH), 2016. Rendszeres internethasználók aránya (2004-2015), downloaded: $19^{\text {th }}$ of April, from the page of https://www.ksh.hu/docs/hun/eurostat tablak/tabl/tin00091.html

Kaushik A., 2007. Web Analytics an hour a day, Wiley Publishing, Inc., Indiana, Canada, pp.193-218

Kaushik A., 2010. Web Analytics 2.0., Wiley Publishing, Inc., Indiana, Canada, pp.299305, pp.348-356

Kotler P., Keller K.L., 2006. Marketingmenedzsment, Akadémia Kiadó, Budapest

Loveday, L., Niehaus S., 2007. Web design for ROI

Majláth, M., Kelemen-Erdős, A., 2015. Marketingkommunikáció, Budapest, Óbudai Egyetem

Malik G., Sachdeva H., 2015. Impact of Sales Promotion Technique Used by Online Dealers on Costumers, International Journal of Applied Science and Management, Vol. 1, no. 1, pp. 63-78., online available:

https://www.waljatcollege.edu.om/journal/pdf/IJASM-010106.pdf

Miller, R. K., Washington K., 2009. Consumer Use Of The Internet \&Mobile Web 2009, Richard K. Miller \& Associates, Loganville, GA, USA, pp.64-93.

Saleh, K., Shukairy, A., 2010. Conversion Optimalization: The Art of science of converting prospects to customers

Szabó, F., 2008. Az internetes aranybánya, Budapest, Redstone Internet Stúdió a Great Mind Solutions Project

Virányi, P., 2014. Több mint reklámtörténelem, Gondolat Kiadó, Budapest 